\title{
ANALISIS FUNGSI KARAKTER DUA TOKOH UTAMA DENGAN TEORI MODEL AKTAN PADA FILM "7 HARI 24 JAM"
}

\author{
Izzati Dwifitriani \\ Endang Mulyaningsih \\ Lilik Kustanto
}

Jurusan Film \& Televisi, Fakultas Seni Media Rekam, Institut Seni Indonesia Yogyakarta J1. Parangtritis km. 6.5 Yogyakarta Telp. (0274) 381047

\section{Pendahuluan}

Setiap cerita atau rangkaian peristiwa pasti memiliki pelaku cerita, masalah, konflik, dan tujuan. Keempatnya merupakan elemen-elemen pokok yang membentuk unsur naratif secara keseluruhan. Elemen-elemen tersebut membentuk sebuah jalinan peristiwa yang terikat hukum kausalitas atau hubungan sebab akibat. Himawan Pratista, dalam bukunya yang berjudul "Memahami Film", mengemukakan bahwa unsur naratif adalah salah satu unsur pembentuk film yang berhubungan dengan aspek tema dan cerita.

Salah satu jenis film yang memiliki unsur atau struktur naratif paling jelas adalah film fiksi. Tidak seperti film dokumenter, narasi di dalam film fiksi tidak membutuhkan realita yang mengandung kebenaran, juga tidak memerlukan adanya penggalian data yang akurat serta fakta yang benarbenar ada. Sesuai dengan istilahnya, maka film fiksi menceritakan sesuatu yang tidak pernah terjadi atau hanya karangan yang bersifat imajiner atau fiktif. Kaminsky menyatakan bahwa film fiksi adalah film yang berdasarkan narasi, baik dari feature film sama dengan filmfilm cerita di televisi, yang lahir dari ideide bersifat fiktif untuk industri hiburan (Pratista: 2008:13).

Namun seperti halnya film dokumenter, cerita film fiksi juga seringkali diangkat dari kisah nyata. Penggambaran kisah nyata dalam film fiksi biasanya diwarnai bumbu-bumbu dramatis dan dibuat sedikit berbeda dari kisah aslinya. Salah satu film layar lebar Indonesia yang diangkat berdasarkan kisah nyata adalah film "7 Hari 24 Jam". Berangkat dari sebuah premis; "angka ganjil dalam pernikahan adalah masamasa yang paling berat", film karya Fajar Nugros ini berkisah tentang pasangan suami istri yang gila bekerja. Meskipun keduanya jarang menghabiskan waktu bersama karena kesibukan masingmasing, pasangan suami istri tersebut tetap menjaga komunikasi dengan saling berkirim kabar melalui telepon. 
Suatu hari keduanya terjebak di dalam satu kamar rumah sakit selama satu minggu. Tokoh suami yang bernama Tyo, divonis dokter terserang penyakit Hepatitis A yang mengharuskannya istirahat total. Sementara itu, istri Tyo yang bernama Tania terpaksa dirawat beberapa hari setelahnya karena terkena tifus akibat kelelahan membagi waktu antara bekerja, mengurus rumah, dan mengurus suaminya yang sedang sakit.

Awalnya, pasangan suami istri yang diperankan oleh Lukman Sardi dan Dian Satrowardoyo ini masih terlihat harmonis. Dirawat di kamar yang sama membuat mereka bisa menghabiskan waktu berdua setelah sekian lama sibuk bekerja. Sampai akhirnya, muncul berbagai macam konflik yang membuat mereka bertengkar hebat. Mulai dari urusan pekerjaan, kecemburuan Tyo pada bos Tania, hingga datangnya mantan kekasih Tyo ke rumah sakit.

Puncak masalah berlangsung saat Tyo dan Tania beradu mulut ketika Tania akan kembali pulang ke rumah. Mereka saling menyalahkan satu sama lain atas apa yang telah terjadi. Tyo yang mulai emosi pun mengeluarkan segelintir kalimat yang menyakiti hati Tania, dan membuat perempuan itu mempertanyakan apakah rumah tangga mereka sebenarnya ada atau tidak. Di akhir cerita, Tyo menyadari bahwa dirinya lah yang salah dan sudah bersikap egois. Ia pun pulang ke rumah di selasela jadwal syutingnya dan meminta maaf pada Tania. Tyo akhirnya mengerti bahwa keluarga yang bahagia merupakan pondasi dari sebuah film yang bagus. Tanpa keluarganya, belum tentu ia bisa menjadi sutradara film sukses seperti sekarang ini.

Ada beberapa hal dalam film "7 Hari 24 Jam" yang menjadi poin menarik, salah satunya adalah setting atau latar tempat yang terbatas. Di awal film, latar tempat yang diperlihatkan hanya lokasi syuting, rumah, dan kantor. Kemudian selama Tyo dan Tania sakit, pengambilan gambar banyak dilakukan di dalam kamar rumah sakit. Di penghujung film, ketika Tyo dan Tania sudah keluar rumah sakit, lokasi syuting dan rumah kembali mewarnai latar tempat dari film tersebut. Hal ini lalu menjadi menarik, sebab film dengan setting terbatas belum banyak diproduksi di Indonesia.

Namun, meski kamar rumah sakit menjadi latar tempat yang paling dominan, ternyata tidak menjadikan film ini membosankan karena kedua tokoh utama memiliki karakter yang khas sehingga dapat menimbulkan konflik. Konflik tersebut kemudian semakin lama semakin besar dan sampai pada titik klimaks. Maka tidak heran bila Dian Sastro \& Lukman Sardi memenangkan 
kategori Best Chemistry di ajang Indonesian Movie Actor Awards 2015. Tanpa chemistry yang kuat dari kedua tokoh utama tersebut, film "7 Hari 24 Jam" mungkin tidak akan menjadi film komedi romantis yang apik dan sederhana.

Perpaduan akting keduanya yang patut diacungi jempol, juga berhasil mengantarkan film ini menjadi nominasi dalam acara Festival Film Bandung 2015 untuk kategori Pemeran Utama Wanita Terpuji (Dian Sastrowardoyo), Piala Maya 2015 untuk kategori Pemeran Utama Wanita Terbaik (Dian Sastrowardoyo), Indonesian Movie Actor Awards 2015 untuk kategori Aktris Favorit dan Aktris Terbaik (Dian Sastrowardoyo), serta kategori Film Favorit di ajang yang sama.

Cerita yang relatif sederhana dan dekat dengan kehidupan sehari-hari, menjadi kompleks karena pengaruh dari konsistensi karakter kedua tokoh utama. Keterbatasan latar tempat menjadi tidak penting lagi karena relasi yang terjalin antara Tyo dan Tania. Banyaknya konflik yang tercipta juga menambah bumbu dramatik sehingga membuat penonton ikut mengalami gejolak emosi tertentu.

Pemaparan di atas merupakan sudut pandang pribadi dari peneliti sebagai seorang penonton. Untuk membuktikannya dari segi keilmuan, maka peneliti pun tertarik untuk menganalisis film "7 Hari 24 Jam" dengan menggunakan teori model aktan. Teori yang dikemukakan oleh Algirdas Julien Greimas ini, akan digunakan untuk menganalisis fungsi karakter dan keterlibatannya pada berbagai peristiwa dalam suatu narasi.

Tidak seperti teori model Propp yang hanya mencari fungsi karakter, teori model aktan juga menekankan pada relasi antara satu karakter dengan karakter lain. Sehingga melalui teori model aktan, hubungan antar tokoh dalam cerita juga dapat dianalisis. Dalam meneliti film ini, mencari fungsi karakter dan relasi antar tokoh menjadi penting untuk mengetahui bagaimana kedudukan dan porsi dari kedua tokoh utama, yakni Tyo dan Tania, yang mendominasi sepanjang film berlangsung.

Setelah mengetahui fungsi karakter dan relasi dari kedua tokoh tersebut, peneliti pun dapat melihat fungsi karakter apakah yang paling banyak diduduki oleh kedua tokoh utama sehingga memicu terjadinya konflik yang berujung klimaks. Atau dengan kata lain, dengan teori model aktan penulis dapat mengetahui bagaimana konsistensi dan perubahan dari kedua tokoh utama dalam film "7 Hari 24 Jam". Untuk melengkapi penelitian, analisis juga akan dilakukan 
menggunakan teori struktur dramatik dan tiga dimensi tokoh.

Penelitian menggunakan metode penelitian kualitatif, yang didefinisikan oleh Moleong sebagai penelitian yang bermaksud untuk memahami fenomena tentang apa yang dialami oleh subjek penelitian misalnya perilaku, persepsi, motivasi, tindakan, dan lain-lain secara holistik dan dengan cara deskripsi dalam bentuk kata- kata dan bahasa, pada suatu konteks khusus yang alamiah dan dengan memanfaatkan berbagai metode (Moleong, 2011:6).

\section{Pembahasan}

\section{Analisis Struktur Dramatik Film "7 Hari 24 Jam"}

\subsection{Teori Struktur Dramatik} Aristoteles

"Struktur" dalam pengertian Latin "structura" merupakan istilah yang terkait dengan konstruksi bangunan, yaitu susunan-susunan material yang menciptakan keutuhan arsitektural bangunan. Sedangkan kata "drama" berasal dari kata Yunani "dran" yang berarti aksi. Struktur dramatik dalam film dapat diartikan sebagai susunan aksi-aksi yang membangun keseluruhan film. Karena yang disusun untuk membangun keutuhan film adalah aksi, maka struktur tidak hanya berhubungan dengan materimateri konkret yang statis, tetapi juga gerak, perubahan, dan perkembangan (Armantono, 2013:157).

Sebuah struktur dramatik dapat dianalisis menggunakan teori konstruksi plot dalam drama. Ide ini pertama kali dikemukakan oleh Aristoteles dalam "Poetics". Hukum komposisi drama menurutnya terdiri atas awal, tengah, dan akhir. Bila dijabarkan lebih lengkap, ada empat tahapan dalam struktur dramatik berdasarkan pendapat Aristoteles yakni protasis (tahap permulaan), epitasio (tahap jalinan kejadian), catastasis (tahap klimaks), serta catastrophe (tahap penutup). Pada penelitian ini, struktur dramatik dalam film "7 Hari 24 Jam" akan dianalisis menggunakan teori konstruksi plot menurut Aristoteles.

\subsection{Struktur Dramatik Film "7}

\section{Hari 24 Jam"}

Aristoteles membagi struktur dramatik dalam sebuah drama menjadi empat tahapan, yaitu protasis (tahap permulaan), epitasio (tahap jalinan kejadian), catastasis (tahap puncak laku atau klimaks), dan catastrophe (tahap penutup). Bila dianalisis menggunakan konstruksi plot milik Aristoteles, maka struktur dramatik dari film "7 Hari 24 Jam" adalah sebagai berikut: 
Tabel 1 Struktur Dramatik Film "7 Hari 24 Jam"

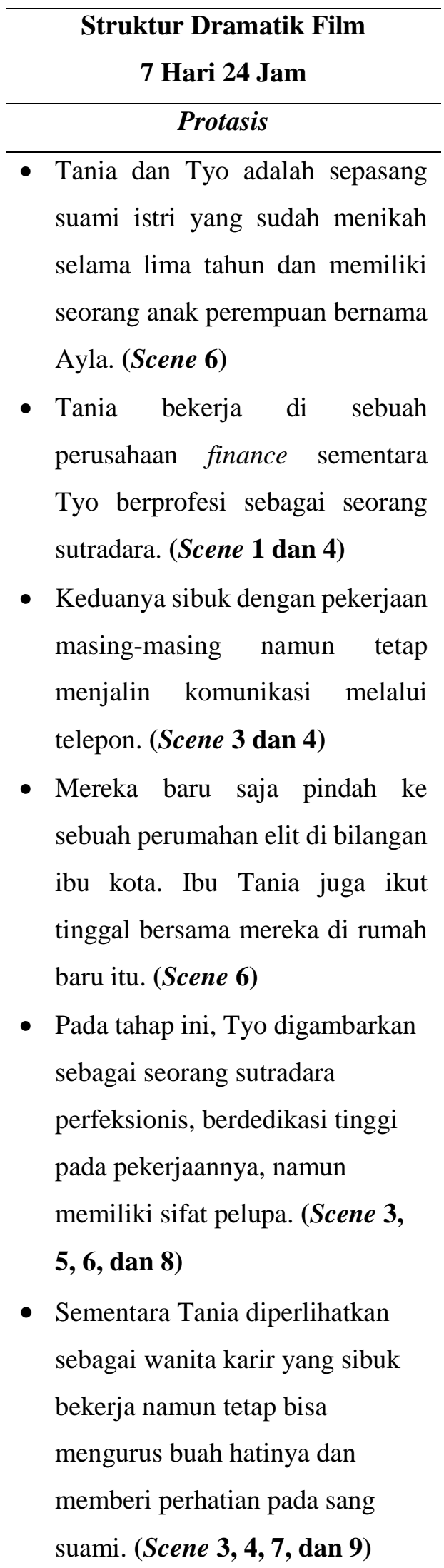

\section{Epitasio}

- Tyo mendadak masuk rumah sakit karena Hepatitis A. Hal ini membuat Tania harus mengeluarkan tenaga ekstra agar bisa mengerjakan pekerjaan kantor sambil mengurus Ayla dan menjaga Tyo di rumah sakit.

\section{(Scene 10-17)}

- Akhirnya Tania ikut dirawat di kamar rumah sakit yang sama karena terkena gejala tifus. Ia juga berada di bawah pengawasan dokter yang sama seperti Tyo. (Scene 18-22)

- Tania meminta teman-teman kantornya datang membawakan pekerjaannya. Tyo pun tak mau kalah, ia menghubungi Adi dan Rizal untuk mengunjunginya di rumah sakit sambil membawa hasil shooting. Peristiwa ini tak sengaja diketahui oleh Dokter Hengky dan Dokter Verdi yang mendadak masuk ke kamar.

\section{(Scene 23-25)}

- Tania mengira Tyo meninggal dunia karena seorang ustad membacakan Surat Yasin di pinggir tempat tidurnya. Namun ternyata ustad tersebut sudah salah masuk kamar. Kejadian ini menyadarkan Tania bahwa dirinya sangat takut kehilangan Tyo. (Scene 26-28)

- Fransiska datang menjenguk Tania dan Tyo. Mereka bertiga 
Izzati Dwifitriani, Endang Mulyaningsih, Lilik Kustanto,

sempat membicarakan tentang pernikahan di tahun ganjil, yang dipercaya merupakan masa-masa terberat bagi pasangan suami istri. Di saat yang sama, Tyo diamdiam meminta Rizal dan Adi datang ke rumah sakit untuk membawakan hasil shooting. Ia mengirimkan pesan kepada Rizal dan Adi melalui ponsel yang diberikan Tania. (Scene 29)

- Pak Haris datang ke rumah sakit untuk meminta Tania melakukan presentasi proposal di depan calon klien melalui video call. Hal ini membuat Tyo sedikit kesal karena merasa Pak Haris tidak menghargainya sebagai suami Tania. (Scene 30)

- Tanpa sepengetahuan Tania, Tyo menyusup keluar kamar menemui kedua orang itu. Mereka bertiga pun menggunakan sebuah ruangan kosong untuk mengecek hasil shooting. Namun ketiganya segera meninggalkan ruangan tersebut saat melihat sesosok mayat terbaring di hadapan mereka. (Scene 32 dan 33)

- Tania mencari Tyo yang tak ada di kamar. Mendadak ia berteriak kencang saat menyadari sebuah ranjang bergerak sendiri di koridor rumah sakit. (Scene 34)

- Tania dan Tyo bertengkar setelah kejadian yang dialami oleh masing-masing. Pertengkaran mereka akhirnya berhenti saat Dokter Verdi dan Dokter Hengky memasuki kamar. Keduanya diberi obat penenang agar bisa istirahat. (Scene 35)

- Video call Tania dengan calon klien gagal total karena tingkah laku aneh Tyo yang terlihat di webcam. Hal ini membuat calon klien merasa tidak nyaman dan akhirnya menyudahi video call tersebut. (Scene 38)

- Tania belum bisa keluar dari rumah sakit sebelum diijinkan oleh Dokter Hengky dan Dokter Verdi. (Scene 40)

- Tyo dijenguk oleh mantan artisnya yang bertingkah genit. Tania yang sedang kesal karena gagalnya video call dengan calon klien, tak memberi komentar apa pun saat melihat Tyo dan si artis genit. (Scene 41)

- Ibu Tania dan Ayla datang menjenguk. Tania memonopoli Ayla sehingga membuat Tyo kesal. (Scene 44)

- Mila, mantan artis Tyo yang pernah memiliki hubungan spesial dengan laki-laki itu, datang menjenguk. Pembicaraan di antara mereka berdua sempat membuat Tania kesal. (Scene 45)

- Tania bersikap dingin pada Tyo meskipun laki-laki itu sudah mencoba mengajaknya berinteraksi. (Scene 46) 


Catastasis
Tania dan Tyo bertengkar hebat saat
Tania hendak pulang ke rumah. Laki-
laki itu mulai tidak tahan dengan
sikap dingin Tania. Ia pun
menanyakan alasan $\quad$ Tania
mendiamkan dirinya. Bahkan ia
menyinggung perihal pekerjaan dan
kedua orang Tania yang sudah
bercerai. Semua omongan yang
keluar dari mulut Tania membuat
perempuan itu naik pitam dan
mempertanyakan pernikahan mereka
yang sudah berjalan selama lima
tahun. Tak lupa ia mengucapkan
terima kasih karena Tyo sudah
berhasil membuatnya kecewa hanya
dalam waktu tujuh hari 24 jam.

(Scene 47)

\begin{tabular}{l}
\hline \multicolumn{1}{c}{ Catastrophe } \\
\hline - Tyo berkeluh kesah pada \\
Fransiska mengenai \\
pertengkarannya dengan Tania. \\
Dari pembicaraannya dengan \\
Fransiska, Tyo jadi mengetahui \\
apa penyebab sikap dingin Tania \\
belakangan ini. (Scene $\mathbf{4 9}$ dan \\
$\mathbf{5 1 )}$ \\
Tania bertanya tentang \\
pernikahan dan masalah \\
keluarganya pada ibunya. Cerita \\
serta nasihat ibunya menyadarkan \\
Tania bahwa pernikahan rawan \\
akan masalah, sehingga \\
membutuhkan kerja sama yang \\
\hline
\end{tabular}

\author{
baik dari kedua belah pihak. \\ Opini ibunya tentang Tyo juga \\ membuat Tania memikirkan \\ kembali pernikahannya dengan \\ Tyo. (Scene 52) \\ - Tyo meninggalkan lokasi \\ shooting untuk pulang dan \\ berbaikan dengan Tania. Tania \\ menerima permintaan maaf Tyo \\ dan keduanya pun kembali akur \\ seperti sedia kala. (Scene 53-55)
}

Berdasarkan tabel di atas, dapat disimpulkan bahwa alur cerita pada film "7 Hari 24 Jam" dari tahap protasis bergerak naik menuju catastasis karena adanya konflik-konflik yang timbul sepanjang tahap epitasio. Konflik adalah dasar dari sebuah plot. Dengan demikian, plot terbangun karena adanya konflikkonflik yang muncul dalam drama (Dewojati, 2012: 193). Pergerakan struktur dramatik juga dapat dilihat pada grafik di halaman selanjutnya.

Konflik pada plot biasanya tercipta karena aksi yang dilakukan oleh para tokoh atau karakter pada cerita dalam mencapai tujuannya. Hal ini dapat terlihat dalam film "7 Hari 24 Jam", di mana sebagian besar konflik datang dari kedua tokoh utama yakni Tyo dan Tania yang terlihat saling berkompetisi untuk mewujudkan keinginan masing-masing. 


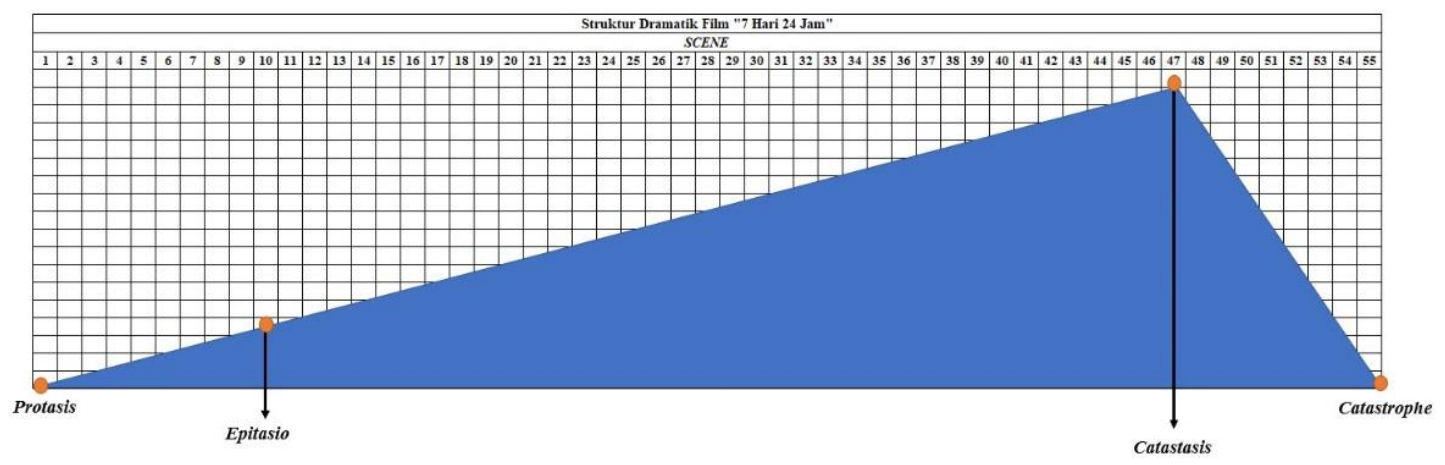

Gambar 1 Grafik Struktur Dramatik Film "7 Hari 24 Jam"

2. Analisis Model Aktan Algirdas Greimas

\subsection{Teori Model Aktan Algirdas Greimas}

Teori mengenai struktur naskah awalnya dikembangkan oleh Vladimir Propp, seorang peneliti dongeng asal Rusia. Ia meneliti dongeng dan ceritacerita rakyat yang ada di Rusia, dengan memotongnya menjadi beberapa bagian. Propp menemukan bahwa setiap cerita memiliki karakter yang menempati fungsi tertentu dalam cerita.

Berdasarkan hasil penelitiannya, sebuah cerita yang sempurna memiliki 31 fungsi dan tujuh karakter. Masingmasing karakter menjalankan fungsi tertentu dalam narasi atau cerita. Hasil penelitian Propp dituangkan dalam sebuah buku berjudul "The Morphology of The Folk Tale" yang diterbitkan pada tahun 1928. Buku tersebut kemudian banyak dipakai oleh para akademisi untuk menjelaskan struktur dalam sebuah naskah.
Selain teori Vladimir Propp, teori lainnya yang biasa digunakan untuk menganalisis struktur naskah adalah teori milik Algirdas Greimas. Ia adalah seorang ahli bahasa asal Lithuania yang berhasil mengembangkan lebih lanjut gagasan milik Propp, dengan memperkenalkan konsep satuan naratif terkecil yang disebut aktan. Teori ini ia terapkan dalam dongeng atau cerita rakyat Rusia.

Greimas melihat narasi sebagai sebuah struktur makna. Bila dianalogikan sebagai sebuah kalimat, maka setiap kata dalam kalimat menempati posisi dan fungsinya masing-masing. Misal sebagai subjek, objek, predikat, dan seterusnya. Sebagai sebuah kesatuan yang koheren, setiap kata dalam kalimat tersebut juga memiliki relasi satu sama lain sehingga menciptakan makna tertentu. Jika analogi tersebut diaplikasikan pada sebuah cerita atau naskah, maka dengan kata lain setiap karakter dalam narasi menempati posisi dan fungsinya masing-masing. Setiap karakter juga memiliki relasi satu sama 
lain, sebagai akibat dari adanya aksireaksi pada sebuah cerita.

$$
\text { Greimas menyederhanakan }
$$

karakterisasi dari model Propp menjadi enam karakter, yakni subjek, objek, pengirim, penerima, pendukung, dan penghambat. Penjelasan mengenai masing-masing karakter dapat dilihat pada tabel berikut ini.

Tabel 2 Tabel Aktan Algirdas Greimas

\begin{tabular}{ll}
\hline Karakter & \multicolumn{2}{c}{ Keterangan } \\
\hline Subjek & $\begin{array}{l}\text { Adalah tokoh utama yang } \\
\text { mengarahkan jalannya sebuah } \\
\text { cerita. }\end{array}$ \\
Objek & $\begin{array}{l}\text { Adalah tujuan yang ingin } \\
\text { dicapai oleh subjek. Dalam teori }\end{array}$ \\
& ini, objek tidak selalu berwujud \\
& manusia tapi juga dapat berupa \\
& keadaan atau kondisi yang \\
& dicita-citakan. \\
Pengirim & $\begin{array}{l}\text { Adalah tokoh yang memberi } \\
\text { aturan atau nilai-nilai dalam } \\
\text { narasi. Umumnya tokoh ini } \\
\text { tidak bertindak secara langsung, } \\
\text { melainkan hanya memberikan } \\
\text { perintah atau aturan-aturan } \\
\text { kepada tokoh dalam narasi. }\end{array}$ \\
Adalah tokoh yang membawa \\
nilai dari pengirim atau dengan \\
kata lain, mengacu kepada \\
objek tempat di mana pengirim \\
menempatkan nilai atau aturan \\
dalam cerita. \\
dalam mencapai tujuan. \\
sebagai pendukung subjek \\
dalam usahanya mencapai \\
objek.
\end{tabular}

Seperti yang sudah dijelaskan pada paragraf sebelumnya, keenam karakter pada model Greimas memiliki hubungan satu sama lain. Bila dibuat dalam bentuk skema, maka akan terlihat bagaimana relasi antar karakter dari model Greimas.

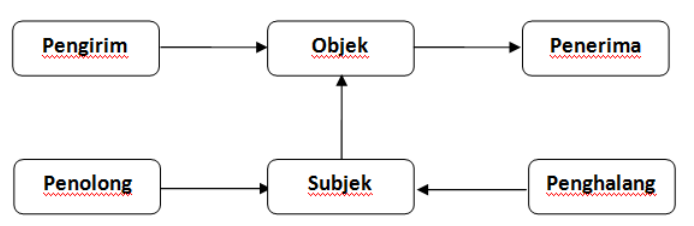

Gambar 2 Skema Model Aktan

Berdasarkan skema tersebut, tercipta sebuah relasi struktural yang oleh Greimas dibagi menjadi tiga jenis relasi, yaitu:

1. Subjek versus Objek (Axis of

\section{Desire)}

Relasi ini menggambarkan objek sebagai tujuan yang ingin dicapai oleh subjek. Hubungan yang terjadi antara subjek dan objek pada relasi ini, dapat berupa hubungan yang dikehendaki oleh kedua belah pihak. Objek yang digambarkan dalam relasi ini tidak selalu harus berupa orang, tetapi juga bisa berupa keadaan.

\section{Pengirim versus Penerima}

\section{(Axis of Transmission)}

Dalam relasi ini, karakter pengirim digambarkan sebagai tokoh yang memberikan nilai, aturan, atau perintah agar objek bisa dicapai. Sementara karakter penerima adalah manfaat yang didapat setelah objek berhasil dicapai oleh subjek. 
3. Pendukung versus Penghambat (Axis of Power)

Karakter pendukung dalam relasi ini dilihat sebagai tokoh yang membantu subjek agar bisa mencapai objek. Sementara penghambat, adalah tokoh yang mencegah subjek mencapai objek.

Berbeda dari model Propp yang bersifat statis, fungsi karakter yang diperkenalkan oleh Greimas lebih dinamis. Artinya, setiap tokoh dapat menduduki fungsi karakter yang berbeda, di mana dalam sebuah cerita bisa terjadi perubahan fungsi karakter. Oleh karena itu, analisis naratif menggunakan model Greimas tidak dapat dilakukan secara keseluruhan melainkan harus dilihat per adegan. Selain peran dari masing-masing karakter, analisis naskah atau cerita dengan model Greimas juga akan memperlihatkan bagaimana kontradiksi dan konsistensi dari setiap tokoh selama cerita berlangsung.

\subsection{Analisis Model}

Aktan

\section{Algirdas Greimas}

Objek dari penelitian ini adalah film panjang berdurasi satu jam 42 menit yang nantinya diurai berdasarkan jumlah scene. Seperti yang dijelaskan oleh Eriyanto dalam bukunya yang berjudul
"Analisis Naratif: Dasar-dasar dan Penerapannya dalam Analisis Teks Berita Media”, untuk menggunakan atau menerapkan model aktan Greimas, peneliti harus mengurai adegan-adegan yang terdapat di dalam film.

Dari masing-masing adegan tersebut akan diuraikan lagi berdasarkan karakter dan fungsi narasinya yakni; objek, subjek, pengirim (destinator), penerima (receiver), pendukung (adjuvant), dan penghambat (traitor). Dalam jurnal ini, uraian adegan akan dibuat dalam bentuk tabel agar lebih ringkas dan memudahkan penghitungan proporsi fungsi aktan dari kedua tokoh utama. Selanjutnya, akan dibuat skema aktan yang menggambarkan relasi antara fungsi karakter tokoh Tania dan tokoh Tyo. Terakhir, fungsi karakter akan dimasukkan ke dalam grafik struktur dramatik untuk melihat bagaimana pengaruhnya terhadap jalan cerita.

\subsection{Tabel Aktan Algirdas Greimas dalam Film "7 Hari 24 Jam" \\ Film "7 Hari 24 Jam” terdiri dari 55 scene, yang jika diurai dalam tabel aktan adalah sebagai berikut:}


Tabel 3 Aktan Film "7 Hari 24 Jam"

\begin{tabular}{|c|c|c|c|c|c|c|c|}
\hline Scene & Adegan & Objek & Subjek & Pengirim & Penerima & Penghambat & Pendukung \\
\hline 1 & $\begin{array}{l}\text { Tyo } \\
\text { mendadak } \\
\text { pingsan di } \\
\text { lokasi syuting }\end{array}$ & $\begin{array}{l}\text { Menyudahi } \\
\text { adegan film }\end{array}$ & $\begin{array}{l}\text { Si artis } \\
\text { perempuan }\end{array}$ & $\begin{array}{l}\text { Si Artis } \\
\text { Perempuan }\end{array}$ & $\begin{array}{l}\mathrm{Si} \text { artis } \\
\text { perempuan }\end{array}$ & $\begin{array}{l}\text { Si artis laki- } \\
\text { laki }\end{array}$ & Tyo \\
\hline 2 & $\begin{array}{l}\text { Tyo dibawa } \\
\text { ke UGD }\end{array}$ & $\begin{array}{l}\text { Kegiatan Tyo } \\
\text { selama } 24 \text { jam } \\
\text { sebelum pingsan }\end{array}$ & $\begin{array}{l}\text { Dokter } \\
\text { Hengky }\end{array}$ & $\begin{array}{l}\text { Dokter } \\
\text { Hengky } \\
\text { Dokter } \\
\text { Verdi }\end{array}$ & $\begin{array}{l}\text { Dokter } \\
\text { Hengky } \\
\text { dan } \\
\text { Dokter } \\
\text { Verdi }\end{array}$ & - & Tania \\
\hline 3 & $\begin{array}{l}\text { Tania } \\
\text { mengingatkan } \\
\text { Tyo untuk } \\
\text { memberi } \\
\text { kabar dan } \\
\text { menduplikat } \\
\text { kunci rumah }\end{array}$ & $\begin{array}{l}\text { Memprotes Tyo } \\
\text { yang tidak } \\
\text { memberi kabar } \\
\text { dan menanyakan } \\
\text { duplikat kunci } \\
\text { rumah }\end{array}$ & Tania & Tyo & Туо & Туо & - \\
\hline 4 & $\begin{array}{l}\text { Tania } \\
\text { menelepon } \\
\text { Tyo dari } \\
\text { kantor }\end{array}$ & $\begin{array}{l}\text { Mengingatkan } \\
\text { Tyo agar tak lupa } \\
\text { minum air putih }\end{array}$ & Tania & Tania & Туо & Тyo & - \\
\hline 5 & $\begin{array}{l}\text { Genset di } \\
\text { lokasi syuting } \\
\text { tiba-tiba } \\
\text { meledak }\end{array}$ & $\begin{array}{l}\text { Menyelesaikan } \\
\text { satu adegan film }\end{array}$ & Туо & Adi & Tyo & $\begin{array}{l}\text { Artis } \\
\text { Para kru } \\
\text { film }\end{array}$ & - \\
\hline 6 & $\begin{array}{l}\text { Tyo pulang } \\
\text { ke rumah }\end{array}$ & $\begin{array}{l}\text { Mengingatkan } \\
\text { Tyo agar tak lupa } \\
\text { makan }\end{array}$ & Tania & Tania & Tyo & Tyo & \\
\hline 7 & $\begin{array}{l}\text { Pak Haris } \\
\text { meminta } \\
\text { Tania } \\
\text { membuat } \\
\text { proposal } \\
\text { untuk calon } \\
\text { klien }\end{array}$ & $\begin{array}{l}\text { Meminta Tania } \\
\text { membuat proposal } \\
\text { pekerjaan }\end{array}$ & Pak Haris & Pak Haris & Pak Haris & - & Tania \\
\hline 8 & $\begin{array}{l}\text { Tyo } \\
\text { mendadak } \\
\text { pingsan di } \\
\text { lokasi syuting }\end{array}$ & $\begin{array}{l}\text { Menyelesaikan } \\
\text { satu adegan yang } \\
\text { sama seperti hari } \\
\text { sebelumnya }\end{array}$ & Тyo & Туо & $\begin{array}{l}\text { Tyo } \\
\text { Kedua } \\
\text { artis Para } \\
\text { kru film }\end{array}$ & $\begin{array}{l}\text { Kedua artis } \\
\text { Tyo }\end{array}$ & - \\
\hline 9 & $\begin{array}{l}\text { Tania } \\
\text { mendapat } \\
\text { kabar perihal } \\
\text { Tyo masuk } \\
\text { UGD }\end{array}$ & $\begin{array}{l}\text { Mempresentasikan } \\
\text { proposalnya pada } \\
\text { Pak Haris }\end{array}$ & Tania & Pak Haris & Tania & Туо & - \\
\hline 10 & $\begin{array}{l}\text { Tyo } \\
\text { didiagnosa } \\
\text { terkena } \\
\text { Hepatitis A }\end{array}$ & $\begin{array}{l}\text { Mengharuskan } \\
\text { Tyo dirawat di } \\
\text { rumah sakit }\end{array}$ & Туо & $\begin{array}{l}\text { Dokter } \\
\text { Hengky }\end{array}$ & $\begin{array}{l}\text { Tyo } \\
\text { Tania } \\
\text { Rizal } \\
\text { Adi }\end{array}$ & - & - \\
\hline 11 & $\begin{array}{l}\text { Tania pergi } \\
\text { ke rumah } \\
\text { sakit }\end{array}$ & $\begin{array}{l}\text { Menginap di } \\
\text { rumah sakit } \\
\text { bersama Tyo }\end{array}$ & Tania & Tania & Туо & - & Ibu Tania \\
\hline 12 & $\begin{array}{l}\text { Pak Haris } \\
\text { menawarkan } \\
\text { Tania untuk } \\
\text { fokus } \\
\text { merawat Tyo }\end{array}$ & $\begin{array}{l}\text { Tania fokus } \\
\text { mengurus Tyo } \\
\text { yang sedang sakit }\end{array}$ & Pak Haris & Pak Haris & Tania & Tania & - \\
\hline
\end{tabular}


Izzati Dwifitriani, Endang Mulyaningsih, Lilik Kustanto,

\begin{tabular}{|c|c|c|c|c|c|c|c|}
\hline 13 & $\begin{array}{l}\text { Tania } \\
\text { menemani } \\
\text { Tyo di rumah } \\
\text { sakit }\end{array}$ & $\begin{array}{l}\text { Menemani Tyo di } \\
\text { rumah sakit }\end{array}$ & Tania & Tania & Tyo & - & - \\
\hline 14 & $\begin{array}{l}\text { Tania sibuk } \\
\text { bekerja dan } \\
\text { mengurus } \\
\text { keluarga }\end{array}$ & $\begin{array}{l}\text { Tetap bekerja } \\
\text { sambil mengurus } \\
\text { anak dan Tyo }\end{array}$ & Tania & Tania & $\begin{array}{l}\text { Ayla } \\
\text { Tyo } \\
\text { Pak Haris }\end{array}$ & - & - \\
\hline 15 & $\begin{array}{l}\text { Tania dan } \\
\text { Tyo hampir } \\
\text { berciuman }\end{array}$ & $\begin{array}{l}\text { Berciuman di atas } \\
\text { tempat tidur }\end{array}$ & $\begin{array}{l}\text { Tania } \\
\text { Tyo }\end{array}$ & $\begin{array}{l}\text { Tania } \\
\text { Tyo }\end{array}$ & - & $\begin{array}{l}\text { Dokter } \\
\text { Verdi }\end{array}$ & - \\
\hline 16 & $\begin{array}{l}\text { Tania tertidur } \\
\text { lagi setelah } \\
\text { mematikan } \\
\text { alarm }\end{array}$ & $\begin{array}{l}\text { Bangun tidur lebih } \\
\text { awal }\end{array}$ & Tania & Tania & Tania & Tania & - \\
\hline 17 & $\begin{array}{l}\text { Tania } \\
\text { terlambat } \\
\text { pergi ke } \\
\text { kantor }\end{array}$ & $\begin{array}{l}\text { Tania sarapan } \\
\text { sebelum ke kantor }\end{array}$ & Tyo & Туо & Tania & Tania & - \\
\hline 18 & $\begin{array}{l}\text { Tania terkena } \\
\text { gejala tifus }\end{array}$ & $\begin{array}{l}\text { Dirawat satu } \\
\text { kamar dengan Tyo }\end{array}$ & $\begin{array}{l}\text { Dokter } \\
\text { Hengky } \\
\text { Dokter } \\
\text { Verdi }\end{array}$ & Tania & $\begin{array}{l}\text { Tyo } \\
\text { Tania }\end{array}$ & - & - \\
\hline 19 & $\begin{array}{l}\text { Tania dirawat } \\
\text { satu kamar } \\
\text { dengan Tyo }\end{array}$ & $\begin{array}{l}\text { Pindah ke ranjang } \\
\text { Tania }\end{array}$ & Туо & Tyo & Tyo & Tania & - \\
\hline 20 & $\begin{array}{l}\text { Tania } \\
\text { memberi } \\
\text { kabar pada } \\
\text { bos dan } \\
\text { teman-teman } \\
\text { kantornya }\end{array}$ & $\begin{array}{l}\text { Memberi kabar } \\
\text { pada Pak Haris } \\
\text { dan teman-teman } \\
\text { kantornya }\end{array}$ & Tania & Tania & Туо & - & - \\
\hline 21 & $\begin{array}{l}\text { Tyo ingin } \\
\text { bermesraan } \\
\text { dengan Tania }\end{array}$ & $\begin{array}{l}\text { Membicarakan } \\
\text { tentang } \\
\text { pernikahan } \\
\text { dengan Tania }\end{array}$ & Tyo & Tyo & Туо & Tania & - \\
\hline 22 & $\begin{array}{l}\text { Tania dan } \\
\text { Tyo } \\
\text { melakukan } \\
\text { video call } \\
\text { dengan Ayla } \\
\text { dan Ibu Tania }\end{array}$ & $\begin{array}{l}\text { Menyapa Ayla } \\
\text { melalui video call }\end{array}$ & $\begin{array}{l}\text { Tania } \\
\text { Tyo }\end{array}$ & $\begin{array}{l}\text { Tania } \\
\text { Tyo }\end{array}$ & $\begin{array}{l}\text { Tania } \\
\text { Tyo }\end{array}$ & Ayla & Ibu Tania \\
\hline 23 & $\begin{array}{l}\text { Tania dan } \\
\text { Tyo bekerja } \\
\text { di kamar } \\
\text { rumah sakit }\end{array}$ & $\begin{array}{l}\text { Tania dan Tyo } \\
\text { mengerjakan } \\
\text { pekerjaan mereka } \\
\text { di kamar rumah } \\
\text { sakit }\end{array}$ & $\begin{array}{l}\text { Tania } \\
\text { Tyo }\end{array}$ & $\begin{array}{l}\text { Tania } \\
\text { Tyo }\end{array}$ & $\begin{array}{l}\text { Tania } \\
\text { Tyo }\end{array}$ & $\begin{array}{l}\text { Dokter } \\
\text { Hengky } \\
\text { Dokter } \\
\text { Verdi }\end{array}$ & $\begin{array}{l}\text { Teman- } \\
\text { teman } \\
\text { kantor } \\
\text { Tania } \\
\text { Para kru } \\
\text { film Tyo }\end{array}$ \\
\hline 24 & $\begin{array}{l}\text { Tania dan } \\
\text { Tyo berdebat } \\
\text { untuk } \\
\text { membela diri }\end{array}$ & $\begin{array}{l}\text { Membela diri } \\
\text { masing-masing }\end{array}$ & $\begin{array}{l}\text { Tania } \\
\text { Tyo }\end{array}$ & $\begin{array}{l}\text { Tania } \\
\text { Tyo }\end{array}$ & $\begin{array}{l}\text { Tania } \\
\text { Tyo }\end{array}$ & - & - \\
\hline 25 & $\begin{array}{l}\text { Tyo } \\
\text { mengeluhkan } \\
\text { kondisinya } \\
\text { pada Tania }\end{array}$ & $\begin{array}{l}\text { Membangunkan } \\
\text { Tania }\end{array}$ & $\begin{array}{l}\text { Tyo } \\
\text { Tania }\end{array}$ & Tyo & Туо & Tania & - \\
\hline 26 & $\begin{array}{l}\text { Tania } \\
\text { mengira Tyo } \\
\text { meninggal } \\
\text { dunia }\end{array}$ & $\begin{array}{l}\text { Tyo meninggal } \\
\text { dunia }\end{array}$ & Tania & Ustaz & $\begin{array}{l}\text { Tania } \\
\text { Tyo }\end{array}$ & Suster & - \\
\hline
\end{tabular}




\begin{tabular}{|c|c|c|c|c|c|c|c|}
\hline 27 & $\begin{array}{l}\text { Tania } \\
\text { melarang Tyo } \\
\text { turun dari } \\
\text { tempat tidur }\end{array}$ & $\begin{array}{l}\text { Tyo dilarang turun } \\
\text { dari tempat tidur }\end{array}$ & Tania & Tania & Tania & - & Туо \\
\hline 28 & $\begin{array}{l}\text { Tania } \\
\text { menanyakan } \\
\text { alasan Tyo } \\
\text { kenapa mau } \\
\text { menikah } \\
\text { dengannya }\end{array}$ & $\begin{array}{l}\text { Alasan Tyo mau } \\
\text { menikah dengan } \\
\text { Tania }\end{array}$ & Tania & Tania & Tania & Туо & Туо \\
\hline 29 & $\begin{array}{l}\text { Fransiska } \\
\text { datang } \\
\text { menjenguk } \\
\text { Tania dan } \\
\text { Tyo }\end{array}$ & $\begin{array}{l}\text { Meminta Rizal } \\
\text { dan Adi datang ke } \\
\text { rumah sakit } \\
\text { melalui SMS }\end{array}$ & Туо & Туо & Туо & - & Tania \\
\hline 30 & $\begin{array}{l}\text { Pak Haris } \\
\text { datang } \\
\text { menjenguk } \\
\text { sekaligus } \\
\text { meminta } \\
\text { Tania untuk } \\
\text { melakukan } \\
\text { video call } \\
\text { dengan calon } \\
\text { klien }\end{array}$ & $\begin{array}{l}\text { Meminta Tania } \\
\text { mempresentasikan } \\
\text { proposal ke calon } \\
\text { klien melalui } \\
\text { video call }\end{array}$ & Pak Haris & Pak Haris & $\begin{array}{l}\text { Pak Haris } \\
\text { Tania }\end{array}$ & Туо & Tania \\
\hline 31 & $\begin{array}{l}\text { Tyo ingin } \\
\text { mendukung } \\
\text { pencapaian } \\
\text { karir Tania }\end{array}$ & $\begin{array}{l}\text { Mendukung karir } \\
\text { Tania }\end{array}$ & Туо & Туо & Tania & - & - \\
\hline 32 & $\begin{array}{l}\text { Rizal dan Adi } \\
\text { menjemput } \\
\text { Tyo di kamar } \\
\text { rumah sakit }\end{array}$ & $\begin{array}{l}\text { Menjemput Tyo di } \\
\text { kamar }\end{array}$ & $\begin{array}{l}\text { Rizal } \\
\text { Adi }\end{array}$ & Туо & Туо & - & $\begin{array}{l}\text { Baju } \\
\text { perawat } \\
\text { Kursi roda }\end{array}$ \\
\hline 33 & $\begin{array}{l}\text { Rizal, Adi, } \\
\text { dan Tyo } \\
\text { mengecek } \\
\text { hasil syuting } \\
\text { di sebuah } \\
\text { ruang gelap }\end{array}$ & $\begin{array}{l}\text { Mengecek hasil } \\
\text { syuting yang } \\
\text { dibawakan Rizal } \\
\text { dan Adi }\end{array}$ & Туо & $\begin{array}{l}\text { Rizal } \\
\text { Adi }\end{array}$ & $\begin{array}{l}\text { Tyo } \\
\text { Rizal } \\
\text { Adi }\end{array}$ & Rizal & $\begin{array}{l}\text { Rizal } \\
\text { Adi }\end{array}$ \\
\hline 34 & $\begin{array}{l}\text { Tania } \\
\text { mencari } \\
\text { keberadaan } \\
\text { Tyo }\end{array}$ & $\begin{array}{l}\text { Mencari } \\
\text { keberadaan Tyo }\end{array}$ & Tania & Туо & Tania & Tania & - \\
\hline 35 & $\begin{array}{l}\text { Tyo dan } \\
\text { Tania } \\
\text { bertengkar } \\
\text { hingga saling } \\
\text { pukul dengan } \\
\text { bantal }\end{array}$ & $\begin{array}{l}\text { Membela diri } \\
\text { masing-masing }\end{array}$ & $\begin{array}{l}\text { Tania } \\
\text { Tyo }\end{array}$ & $\begin{array}{l}\text { Tania } \\
\text { Tyo }\end{array}$ & $\begin{array}{l}\text { Tania } \\
\text { Tyo }\end{array}$ & $\begin{array}{l}\text { Dokter } \\
\text { Verdi } \\
\text { Dokter } \\
\text { Hengky }\end{array}$ & - \\
\hline 36 & $\begin{array}{l}\text { Dokter } \\
\text { memberi obat } \\
\text { penenang } \\
\text { pada Tyo dan } \\
\text { Tania }\end{array}$ & $\begin{array}{l}\text { Memberi obat } \\
\text { penenang pada } \\
\text { Tyo dan Tania }\end{array}$ & $\begin{array}{l}\text { Dokter } \\
\text { Hengky } \\
\text { Dokter } \\
\text { Verdi }\end{array}$ & $\begin{array}{l}\text { Petugas } \\
\text { rumah } \\
\text { sakit }\end{array}$ & $\begin{array}{l}\text { Tyo } \\
\text { Tania }\end{array}$ & - & Suster \\
\hline 37 & $\begin{array}{l}\text { Persiapan } \\
\text { video call } \\
\text { Tania dengan } \\
\text { calon klien }\end{array}$ & $\begin{array}{l}\text { Memastikan Tania } \\
\text { siap melakukan } \\
\text { video call }\end{array}$ & Pak Haris & Pak Haris & Pak Haris & - & Tania \\
\hline 38 & $\begin{array}{l}\text { Tania } \\
\text { melakukan } \\
\text { video call }\end{array}$ & $\begin{array}{l}\text { Melakukan } \\
\text { meeting melalui } \\
\text { video call bersama } \\
\text { calon klien }\end{array}$ & $\begin{array}{l}\text { Tania } \\
\text { Pak Haris }\end{array}$ & $\begin{array}{l}\text { Pak Haris } \\
\text { Tania }\end{array}$ & $\begin{array}{l}\text { Tania } \\
\text { Pak Haris }\end{array}$ & Туо & - \\
\hline
\end{tabular}


Izzati Dwifitriani, Endang Mulyaningsih, Lilik Kustanto,

\begin{tabular}{|c|c|c|c|c|c|c|c|}
\hline 39 & $\begin{array}{l}\text { dengan calon } \\
\text { klien baru } \\
\text { Tyo mencari } \\
\text { Tania yang } \\
\text { tidak ada di } \\
\text { kamar }\end{array}$ & Mencari Tania & Туо & Tania & Туо & Туо & - \\
\hline 40 & $\begin{array}{l}\text { Tania belum } \\
\text { bisa keluar } \\
\text { dari rumah } \\
\text { sakit }\end{array}$ & $\begin{array}{l}\text { Keluar dari rumah } \\
\text { sakit secepatnya }\end{array}$ & Tania & Tania & Tania & $\begin{array}{l}\text { Dokter } \\
\text { Hengky } \\
\text { Dokter } \\
\text { Verdi }\end{array}$ & - \\
\hline 41 & $\begin{array}{l}\text { Tyo dijenguk } \\
\text { oleh mantan } \\
\text { artisnya yang } \\
\text { genit }\end{array}$ & Menjenguk Tyo & $\begin{array}{l}\text { Si artis } \\
\text { genit }\end{array}$ & Rizal & Туо & - & Туо \\
\hline 42 & $\begin{array}{l}\text { Tania } \\
\text { mendiamkan } \\
\text { Tyo }\end{array}$ & $\begin{array}{l}\text { Ingin tahu } \\
\text { mengapa Tania } \\
\text { tak mau bicara } \\
\text { dengannya }\end{array}$ & Туо & Туо & Туо & Tania & - \\
\hline 43 & $\begin{array}{l}\text { Kondisi } \\
\text { Tania dan } \\
\text { Tyo mulai } \\
\text { membaik }\end{array}$ & $\begin{array}{l}\text { Kondisi Tania dan } \\
\text { Tyo yang terus } \\
\text { membaik }\end{array}$ & $\begin{array}{l}\text { Dokter } \\
\text { Hengky } \\
\text { Dokter } \\
\text { Verdi }\end{array}$ & $\begin{array}{l}\text { Dokter } \\
\text { Hengky } \\
\text { Dokter } \\
\text { Verdi }\end{array}$ & $\begin{array}{l}\text { Tyo } \\
\text { Tania }\end{array}$ & - & - \\
\hline 44 & $\begin{array}{l}\text { Ayla dan Ibu } \\
\text { Tania datang } \\
\text { menjenguk }\end{array}$ & $\begin{array}{l}\text { Bercengkrama } \\
\text { dengan Ayla }\end{array}$ & $\begin{array}{l}\text { Tyo } \\
\text { Tania }\end{array}$ & $\begin{array}{l}\text { Tyo } \\
\text { Tania }\end{array}$ & Туо & Tania & - \\
\hline 45 & $\begin{array}{l}\text { Mila datang } \\
\text { menjenguk } \\
\text { Tyo }\end{array}$ & $\begin{array}{l}\text { Menjenguk dan } \\
\text { berbincang } \\
\text { dengan Tyo }\end{array}$ & Mila & Artis lain & $\begin{array}{l}\text { Mila } \\
\text { Tyo }\end{array}$ & Tania & - \\
\hline 46 & $\begin{array}{l}\text { Tania masih } \\
\text { bersikap } \\
\text { dingin pada } \\
\text { Tyo }\end{array}$ & $\begin{array}{l}\text { Berinteraksi } \\
\text { dengan Tania }\end{array}$ & Туо & Tyo & Туо & Tania & - \\
\hline 47 & $\begin{array}{l}\text { Tania dan } \\
\text { Tyo } \\
\text { bertengkar } \\
\text { hebat }\end{array}$ & $\begin{array}{l}\text { Meributkan } \\
\text { masalah yang } \\
\text { terjadi di } \\
\text { pernikahan } \\
\text { mereka }\end{array}$ & $\begin{array}{l}\text { Tyo } \\
\text { Tania }\end{array}$ & Tyo & Туо & $\begin{array}{l}\text { Tyo } \\
\text { Tania }\end{array}$ & $\begin{array}{l}\text { Tyo } \\
\text { Tania }\end{array}$ \\
\hline 48 & $\begin{array}{l}\text { Dokter } \\
\text { Hengky } \\
\text { membolehkan } \\
\text { Tyo dan } \\
\text { Tania pulang }\end{array}$ & $\begin{array}{l}\text { Tyo dan Tania } \\
\text { dibolehkan pulang }\end{array}$ & $\begin{array}{l}\text { Dokter } \\
\text { Hengky }\end{array}$ & $\begin{array}{l}\text { Tyo } \\
\text { Tania }\end{array}$ & Туо & - & - \\
\hline 49 & $\begin{array}{l}\text { Tyo } \\
\text { melakukan } \\
\text { curahan hati } \\
\text { pada } \\
\text { Fransiska }\end{array}$ & $\begin{array}{l}\text { Menceritakan } \\
\text { masalahnya pada } \\
\text { Fransiska }\end{array}$ & Tyо & Туо & Туо & - & Fransiska \\
\hline 50 & $\begin{array}{l}\text { Dokter } \\
\text { Hengky } \\
\text { memuji } \\
\text { kinerja } \\
\text { Dokter Verdi }\end{array}$ & $\begin{array}{l}\text { Melepas masa } \\
\text { supervisinya } \\
\text { terhadap Dokter } \\
\text { Verdi }\end{array}$ & $\begin{array}{l}\text { Dokter } \\
\text { Hengky }\end{array}$ & $\begin{array}{l}\text { Dokter } \\
\text { Verdi }\end{array}$ & $\begin{array}{l}\text { Dokter } \\
\text { Verdi }\end{array}$ & Suster UGD & - \\
\hline 51 & $\begin{array}{l}\text { Tyo keluar } \\
\text { dari rumah } \\
\text { sakit }\end{array}$ & $\begin{array}{l}\text { Kembali ke lokasi } \\
\text { syuting }\end{array}$ & Туо & Tyo & - & - & $\begin{array}{l}\text { Rizal } \\
\text { Adi }\end{array}$ \\
\hline 52 & $\begin{array}{l}\text { Tania } \\
\text { berkeluh } \\
\text { kesah perihal } \\
\text { rumah tangga } \\
\text { pada ibunya }\end{array}$ & $\begin{array}{l}\text { Berkeluh kesah } \\
\text { pada ibunya } \\
\text { tentang } \\
\text { pernikahan }\end{array}$ & Tania & Туо & $\begin{array}{l}\text { Tyo } \\
\text { Tania }\end{array}$ & - & Ibu Tania \\
\hline
\end{tabular}




\begin{tabular}{|c|c|c|c|c|c|c|c|}
\hline 53 & $\begin{array}{l}\text { Tyo tak bisa } \\
\text { mengarahkan } \\
\text { kedua } \\
\text { artisnya }\end{array}$ & $\begin{array}{l}\text { Mengarahkan } \\
\text { kedua artisnya } \\
\text { untuk mengerti } \\
\text { tentang cinta }\end{array}$ & Туо & Туо & Туо & Туо & Rizal \\
\hline 54 & $\begin{array}{l}\text { Tania } \\
\text { mencari Ayla } \\
\text { dan ibunya }\end{array}$ & Mencari Ayla & Tania & Ayla & Tania & - & - \\
\hline 55 & $\begin{array}{l}\text { Tania dan } \\
\text { Tyo } \\
\text { berbaikan }\end{array}$ & $\begin{array}{l}\text { Berbaikan dengan } \\
\text { Tania }\end{array}$ & Туо & Tyo & $\begin{array}{l}\text { Tyo } \\
\text { Tania } \\
\text { Ayla }\end{array}$ & - & Tania \\
\hline
\end{tabular}

Berdasarkan tabel di atas, dapat dihitung proporsi fungsi karakter yang diisi oleh Tania dan Tyo. Hasil penghitungan fungsi karakter dari kedua tokoh utama ini dapat dilihat pada tabel di halaman selanjutnya.

Tabel 4 Hasil Akhir Proporsi Fungsi Karakter Tyo dan Tania

\begin{tabular}{cccccc}
\hline \multirow{2}{*}{ Tokoh } & \multicolumn{5}{c}{ Fungsi Karakter } \\
& Subjek & Pengirim & Penerima & Penghambat & Pendukung \\
\hline Tyo & 24 & 24 & 36 & 11 & 5 \\
Tania & 25 & 20 & 23 & 12 & 7 \\
\hline
\end{tabular}

Dari total 55 scene yang ada di dalam film 7 Hari 24 Jam, fungsi karakter atau aktan subjek paling banyak diisi oleh tokoh Tyo yakni berjumlah 24 kali. Sementara tokoh Tania menempati aktan subjek sebanyak 25 kali. Perhitungan ini dapat dicek pada tabel skema aktan yang sudah dibuat pada sub-bab sebelumnya. Meski terdapat perbedaan jumlah, namun data ini menunjukkan bahwa Tyo dan Tania mendominasi jalan cerita. Keduanya sama-sama memiliki tujuan atau objek tertentu yang ingin dicapai.
Bahkan Tyo dan Tania mengisi aktan subjek secara bersamaan di beberapa adegan seperti pada scene 23, 24 , dan 25. Salah satunya dapat dilihat pada scene 23, saat dokter Hengky dan Dokter Verdi memergoki keduanya sedang melakukan pekerjaan dengan teman-teman kantor dan para kru film. Di adegan ini Tyo dan Tania sama-sama menempati aktan subjek karena ada objek yang ingin mereka raih yaitu menyelesaikan pekerjaan mereka. Skema aktan saat Tyo dan Tania mengisi subjek dapat dilihat pada gambar berikut: 
Izzati Dwifitriani, Endang Mulyaningsih, Lilik Kustanto,

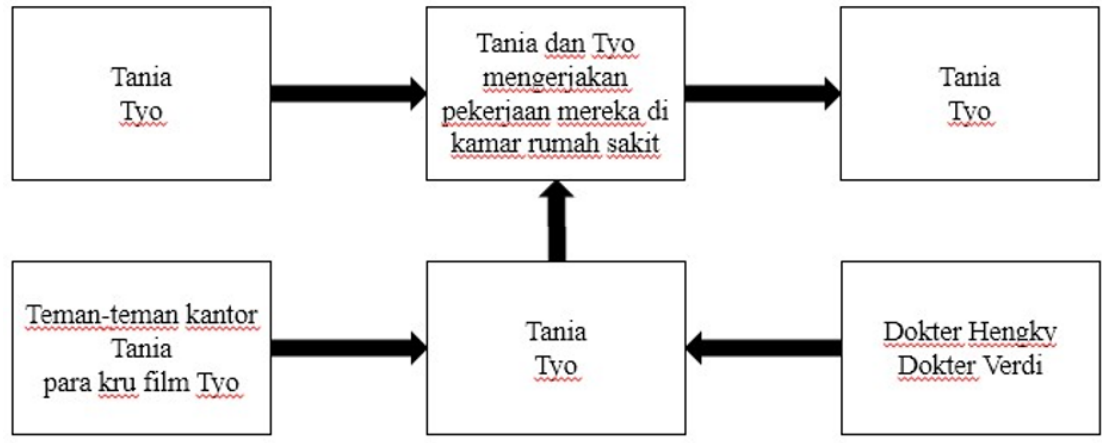

Skema Aktan Tyo dan Tania sebagai subjek

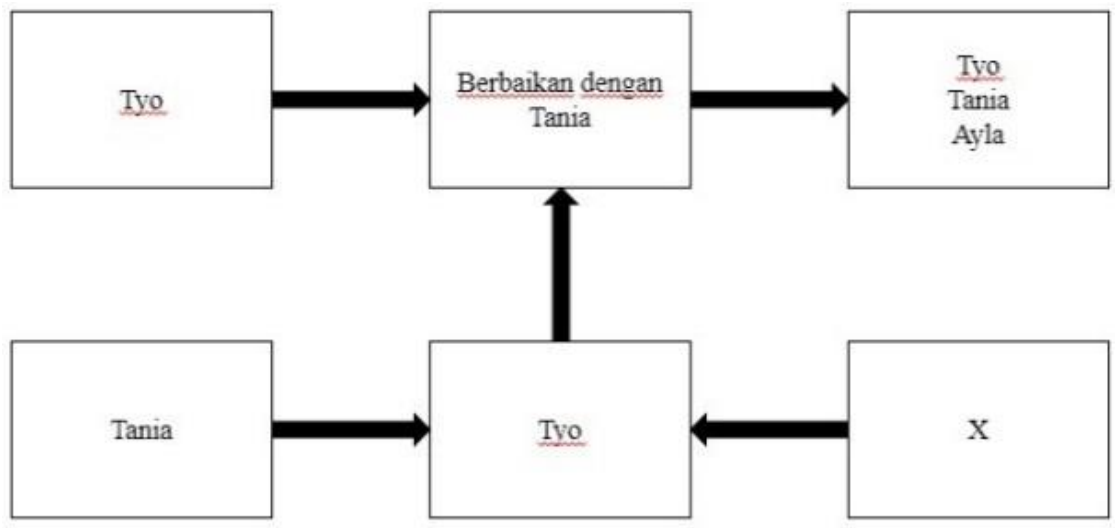

Skema Aktan Tyo sebagai pengirim

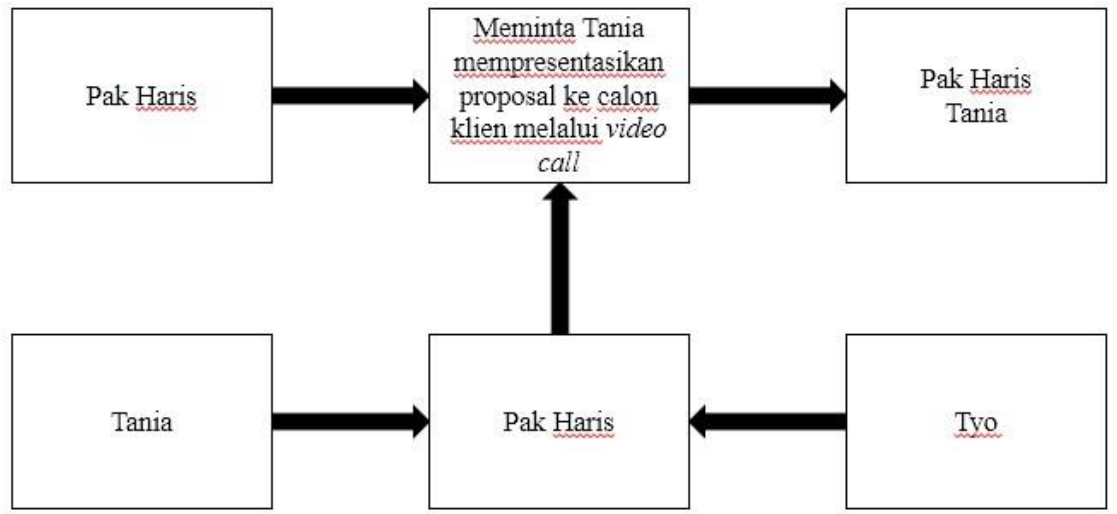

Skema Aktan Tania sebagai penerima

Keinginan Tyo dan Tania dalam mencapai sebuah objek dipengaruhi oleh aktan pengirim, yang ternyata paling sering diisi oleh mereka sendiri. Atau dengan kata lain perintah dan nilai-nilai yang diberikan pada subjek untuk mencapai objek, banyak berasal dari dalam diri si tokoh. Misal pada adegan Tyo dan Tania akhirnya berbaikan setelah bertengkar hebat. Aktan subjek diisi oleh 148
Tyo yang memiliki objek untuk meminta maaf pada Tania. Di sini, aktan pengirim berasal dari dalam diri Tyo yakni rasa sayangnya pada Tania. Perasaan itulah yang mendorongnya untuk melakukan aksi pulang ke rumah dan berbaikan dengan Tania. Berikut adalah salah satu skema aktan Tyo sebagai pengirim.

Selain aktan pengirim, Tyo dan Tania juga berperan sebagi aktan 
penerima dalam beberapa adegan. Fakta ini menjadi penanda, apabila sebuah objek berhasil tercapai atau tidak oleh aktan subjek, maka Tyo dan Tania akan menerima manfaat atau akibat dari aksi yang dilakukan subjek. Contohnya dapat dilihat dalam adegan Pak Haris datang berkunjung ke rumah sakit. Sebagai subjek, Pak Haris memiliki objek untuk menjenguk Tania sekaligus memintanya melakukan presentasi melalui video call ke calon klien. Tanpa pikir panjang Tania langsung menerima tawaran tersebut. Baginya ini adalah sebuah kesempatan untuk membuktikan pada Pak Haris bahwa dirinya tetap bisa melakukan pekerjaan meski sedang dirawat di rumah sakit. Pada scene berikutnya pun dijelaskan, apabila meeting dengan calon klien ini berhasil, maka Tania akan dipertimbangkan untuk naik jabatan. Oleh karena itu, aktan penerima diisi oleh Tania sebab ia menerima manfaat dari apa yang ditawarkan oleh Pak Haris. Berikut adalah skema aktan dari Tania saat mengisi fungsi penerima:

Dalam cerita juga diperlihatkan bagaimana kedua tokoh ini mengisi aktan pendukung. Bila dihitung berdasarkan skema aktan, Tania menempati aktan pendukung sebanyak tujuh kali sementara Tyo lima kali. Dengan kata lain, tokoh Tania lebih sering membantu subjek mencapai objek daripada Tyo. Tetapi di sisi lain, skema aktan juga menunjukkan tokoh Tania mengisi aktan penghambat hingga 12 kali, sedangkan Tyo sebanyak 11 kali. Meski selisih angka dari data tersebut hanya berbeda satu, namun hal ini menunjukkan bahwa meski Tania menempati fungsi aktan pendukung lebih banyak daripada Tyo, namun ia juga lebih sering menghalangi subjek mencapai objek bila dibandingkan dengan Tyo.

Berdasarkan penjabaran di atas, dapat disimpulkan bahwa kedua tokoh utama dalam film "7 Hari 24 Jam" mengalami perubahan fungsi karakter pada beberapa adegan. Meskipun begitu, fungsi karakter sebagai subjek menjadi posisi yang paling sering ditempati oleh Tyo dan Tania. Konsistensi ini menjadikan mereka sebagai penggerak cerita yang paling dominan sepanjang film berlangsung.

\section{Relasi Fungsi Karakter dengan Struktur Dramatik}

Fungsi karakter yang dimiliki oleh Tyo dan Tania juga memberi pengaruh pada pergerakan struktur dramatik dalam film karena menciptakan banyak konflik. Keduanya seringkali bertengkar saat salah satu pihak mengisi aktan subjek sementara pihak yang lain mengisi aktan penghambat. Persaingan ketat di antara keduanya dalam meraih objek menimbulkan berbagai macam 
Izzati Dwifitriani, Endang Mulyaningsih, Lilik Kustanto,

Analisis Fungsi Karakter Dua Tokoh Utama Dengan Teori Model Aktan Pada Film "7 Hari 24 Jam"

masalah sehingga konflik mencapai titik klimaks atau tahap catastasis.

Masalah di antara Tania dan Tyo sudah dimulai bahkan di tahap protasis. Pada scene tiga, empat, enam, dan sembilan, Tania mengisi aktan subjek sementara Tyo mengisi aktan penghambat. Struktur dramatik pun bergerak menuju titik epitasio. Pada tahap selanjutnya, Tania mengalami perubahan fungsi karakter di beberapa adegan. Ia lebih banyak mengisi aktan penghambat sementara Tyo menjadi aktan subjek. Hal ini dapat dilihat pada scene 17, 19, 21, 25, 42, 44, dan 46. Akibatnya alur cerita bergerak naik dari epitasio menuju catastasis.

Masalah-masalah yang sudah terjadi sepanjang tahap protasis dan epitasio akhirnya sampai di titik klimaks. Pada scene 47, Tania dan Tyo sama-sama mengisi aktan subjek sebab keduanya memiliki objek yang sama yakni membela diri masing-masing. Selain menjadi aktan subjek, pada scene ini Tania dan Tyo juga mengisi aktan penghambat yang menyebabkan pertengkaran di antara keduanya terus berlanjut hingga Tania akhirnya memutuskan pergi dari kamar rumah sakit. Sifat keras kepala yang dimiliki keduanya ikut mendukung terjadinya konflik pada adegan ini.

Setelah titik klimaks, tensi cerita pun menurun seiring berjalannya struktur dramatik menuju tahap penutup atau catastrophe. Tak ada lagi pertemuan antara Tania sebagai subjek dan Tyo sebagai penghambat atau pula sebaliknya. Hal ini menandakan bahwa konflik di antara mereka sudah berada pada masa penyelesaian. Kedudukan fungsi karakter serta pengaruhnya terhadap pergerakan dramatik dapat dilihat pada grafik yang terdapat di halaman selanjutnya.

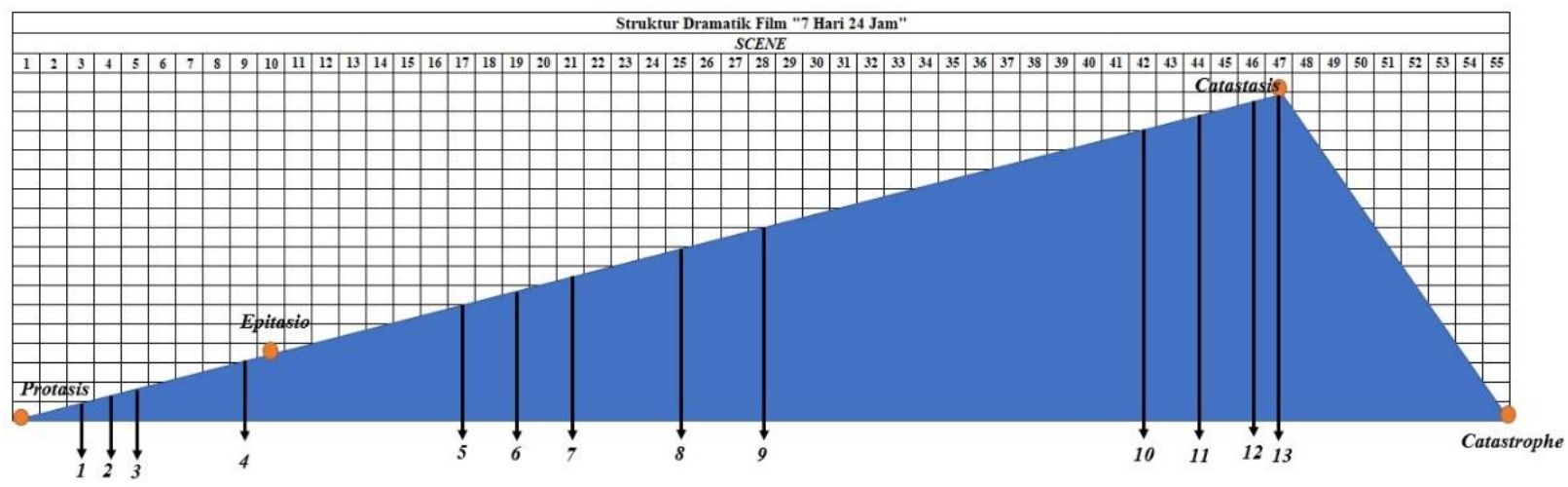

Keterangan:

- Tania sebagai subjek dan Tyo sebagai penghambat: 1, 2, 3, 4, 9

- Tyo sebagai subjek dan Tania sebagai penghambat: 5, 6, 7, 8, 10, 11, 12

- Tania dan Tyo sebagai subjek dan penghambat: 13 
Selain memberi pengaruh pada pergerakan konflik, fungsi karakter dari kedua tokoh utama juga menciptakan struktur dramatik yang baik pada film "7 Hari 24 Jam”. Mengacu pada penjabaran RB Armantono dan Suryana Paramita dalam buku mereka yang berjudul "Skenario: Teknik Penulisan Struktur Cerita Film", struktur dramatik yang baik adalah menempatkan peristiwa-peristiwa sedemikian rupa sehingga peristiwa berikutnya harus lebih menarik dibanding peristiwa sebelumnya.

Struktur yang baik menempatkan peristiwa-peristiwa pada posisi yang tepat untuk membangkitkan kertelibatan emosional yang maksimal dari penonton. Oleh karena itu, setiap karakterisasi harus tumbuh menuju akhir. Setiap emosi harus secara gradual semakin kuat. Setiap keputusan harus semakin penting. Semua elemen dramatik disusun semakin lama semakin meningkat menuju ke puncak dramatik yang dikenal dengan istilah klimaks (Armantono, Suryana, 2013:158-159).

Ketatnya persaingan di antara Tyo dan Tania sebagai aktan subjek dan penghambat dalam meraih tujuan, menimbulkan pergerakan konflik yang terus naik sehingga jalan cerita menjadi lebih dinamis. Setting yang terbatas tak lagi menjadi masalah sebab intensitas konflik di antara Tyo dan Tania membuat alur cerita semakin menarik untuk disimak.

\section{Kesimpulan}

Berdasarkan hasil analisis struktur dramatik pada bab pembahasan, dapat disimpulkan bahwa alur cerita film bergerak naik dari protasis menuju catastasis karena konflik-konflik yang timbul sepanjang tahap epitasio. Pada film "7 Hari 24 Jam", sebagian besar konflik datang dari kedua tokoh utama yakni Tyo dan Tania. Masalah yang terjadi di antara keduanya, turut didukung oleh kesamaan dimensi psikologis dari Tyo dan Tania yakni sama-sama keras kepala dan pekerja keras. Pertengkaran di antara Tyo dan Tania seringkali tak bisa dihindari karena masing- masing merasa paling benar dan tak ada yang mau mengalah. Watak yang dimiliki kedua tokoh ini ikut memperkuat intensitas konflik pada jalan cerita.

Kemudian setelah ditinjau dengan teori model aktan, didapatkan hasil akhir bahwa kedua tokoh utama paling sering menduduki aktan subjek. Hal ini menunjukkan bahwa Tyo dan Tania memiliki objek atau tujuan yang ingin diraih. Bahkan di beberapa scene, mereka menempati aktan subjek secara bersamaan sebab mempunyai satu objek yang sama. Meskipun begitu, keduanya juga mengalami perubahan fungsi karakter sepanjang cerita berlangsung. 
Hal ini dapat dilihat pada tabel hasil penghitungan fungsi karakter di bab pembahasan.

Konsistensi serta perubahan fungsi karakter yang dialami oleh Tyo dan Tania turut mewarnai struktur dramatik dengan memberikan pergerakan konflik. Pada film ini, sebagian besar konflik terjadi karena adanya persinggungan antara fungsi karakter dari tokoh Tyo dan Tania. Berdasarkan grafik dan penjabaran di sub-bab hasil akhir pada bab pembahasan, terlihat bahwa konflik terjadi saat Tyo mengisi aktan subjek dan Tania mengisi aktan penghambat ataupun sebaliknya. Hal ini menyebabkan intensitas masalah dan konflik menjadi semakin tinggi sehingga struktur dramatik bergerak naik mencapai klimaks.

Alur cerita bergerak maju dari tahap protasis menuju catastasis karena adanya konflik-konflik, yang didasari oleh aksi para tokoh saat berupaya mencapai tujuan masing-masing. Sehingga dapat disimpulkan bahwa fungsi karakter dari kedua tokoh utama memberikan motif pada cerita dalam bentuk konflik sehingga alur film menjadi lebih dinamis dan menarik untuk disimak.

\section{Daftar Pustaka}

Armantono, RB, Suryana Paramita. 2013. Skenario, Teknik Penulisan Struktur Cerita Film. Jakarta: FFTV IKJ.

Biran, H. Misbach Yusa. 2007. Teknik Menulis Skenario Film Cerita. Jakarta: Pustaka Jaya.

Boggs, Joseph M. 2008. The Art of Watching Film. New York: McGraw-Hill. Dewojati, Cahyaningrum. 2012. Drama: Sejarah, Teori, dan Penerapannya. Javakarsa Media

Eriyanto. 2003. Analisis Naratif: Dasardasar dan Penerapannya dalam Analisis Teks Berita Media. Jakarta: Prenamedia Group.

Egri, Lajos. 1960. The Art Dramatic Writing. US: Simon \& Schuster, Inc. Harymawan, RMA. 1993. Dramaturgi. Bandung: PT Remaja Rosdakarya. Liliweri, Alo. 2004. Dasar-dasar Komunikasi Antarbudaya. Yogyakarta: Pustaka Pelajar.

Lutters, Elizabeth. 2006. Kunci Sukses Menulis Skenarion. Jakarta: PT. Grasindo.

Moleong, L.J. 2011. Metodologi Penelitian Kualitatif Edisi Revisi. Bandung: PT. Remaja Rosdakarya Nurgiyantoro, Burhan. 2012. Teori Pengkajian Fiksi. Yogyakarta: Gadjah Mada University Press.

Pratista, Himawan. 2008. Memahami Film. Yogyakarta: Homerian Pustaka. Suwasono, A.A. 2014. Pengantar Film. Yogyakarta: Badan Penerbit ISI Yogyakarta. 


\section{Skripsi}

Ulfa, Maria. "Analisis Perbandingan Struktur Aktan Versi Film dan Versi Sinetron "Surat Kecil untuk Tuhan"." Institut Seni Indonesia Yogyakarta, 2014

Saraswati, Marissa. "Struktur Penokohan dan Ideologi Gender dalam Shrek." Universitas Indonesia, 2007.

Rusmawati, Fatimah. 2014. "Analisa Naratif Film Miracle In Cell No. 7 dengan Teori Algirdas

Greimas." Universitas Telkom Bandung, 2007. 